Fixed Point Theory, 18(2017), No. 2, 721-728

DOI $10.24193 /$ fpt-ro.2017.2.58

http://www.math.ubbcluj.ro/ ${ }_{\text {nodeacj/sfptcj.html }}$

\title{
FIXED POINTS, NORMAL STRUCTURE AND SLICES OF BANACH SPACES
}

\author{
SATIT SAEJUNG* AND JI GAO**,1 \\ *Department of Mathematics, Faculty of Science \\ Khon Kaen University, Khon Kaen 40002, Thailand \\ E-mail: saejung@kku.ac.th \\ **Department of Mathematics, Community College of Philadelphia \\ Philadelphia, PA 19130-3991, USA \\ E-mail: jgao@ccp.edu
}

Abstract. In this paper, we first study the fixed point property for nonexpansive mappings of a Banach space and some existing result in [7] is extended. We secondly study the relationship between uniform normal structure and slices and some results in [11] are improved too.

Key Words and Phrases: Nonexpansive mapping, normal structure, ultraproduct, uniform normal structure, WORTH property.

2010 Mathematics Subject Classification: 46B20, 47H10, 37C25, 54H25.

\section{REFERENCES}

[1] A.G. Aksoy, M.A. Khamsi, Nonstandard Methods in Fixed Point Theory, Universitext, SpringerVerlag, New York, 1990

[2] M.S. Brodskiǔ, D.P. Mil'man, On the center of a convex set, Doklady Akad. Nauk SSSR (N.S.), 59(1948), 837-840.

[3] D. Dacunha-Castelle, J.L. Krivine, Applications des ultraproduits à l'étude des espaces et des algèbres de Banach, Studia Math., 41(1972), 315-334.

[4] J. Diestel, The Geometry of Banach Spaces - Selected Topics, Lecture Notes in Math., Vol. 485, Spring Verlag, Berlin and New York, 1975.

[5] H. Fetter, B. Gamboa de Buen, Properties WORTH and WORTH*, $(1+\delta)$ embeddings in Banach spaces with 1-unconditional basis and wFPP, Fixed Point Theory Appl., 2010, Art. ID 342691, 7 pp.

[6] K. Goebel, W.A. Kirk, Topics in Metric Fixed Point Theory, Cambridge Studies in Advanced Mathematics, 28. Cambridge University Press, Cambridge, 1990.

[7] A. Jiménez-Melado, The fixed point property for some uniformly nonoctahedral Banach spaces, Bull. Austral. Math. Soc., 59(1999), 361-367.

[8] W.A. Kirk, A fixed point theorem for mappings which do not increase distances, Amer. Math. Monthly, 72(1965), 1004-1006.

[9] P.K. Lin, Unconditional bases and fixed points of nonexpansive mappings, Pacific J. Math., 116(1985), 69-76.

\footnotetext{
${ }^{1}$ Corresponding author.
} 
[10] S. Saejung, Convexity conditions and normal structure of Banach spaces, J. Math. Anal. Appl., 344(2008), 851-856.

[11] S. Saejung, J. Gao, Normal structure, slices and other properties in Banach spaces, WSEAS Trans. on Mathematics, 11(2012), 1094-1102.

[12] B. Sims, "Ultra"-techniques in Banach Space Theory, Queen's Papers in Pure and Applied Mathematics, 60, Queen's University, Kingston, ON, 1982.

[13] B. Sims, A class of spaces with weak normal structure, Bull. Austral. Math. Soc., 49(1994), $523-528$.

Received: August 22, 2014; Accepted: January 8, 2015. 
